\title{
PERBANDINGAN METODE NAÏVE BAYES DAN C4.5 UNTUK MEMPREDIKSI MORTALITAS PADA PETERNAKAN AYAM BROILER
}

\author{
Dimas Imam Baihaqi \\ Fakultas Teknik, Program Studi Teknik Informatika \\ Universitas Negeri Malang \\ Email: dimas.bai9@gmail.com
}

Anik Nur Handayani

Jurusan Elektro

Universitas Negeri Malang

Email: anik.nur.ft@um.ac.id

Utomo Pujianto

Jurusan Elektro

Universitas Negeri Malang

Email: utomo.pujianto.ft@um.ac.id

\begin{abstract}
ABSTRAK
Ayam broiler adalah jenis ternak yang paling cepat untuk dipanen. Namun dalam berternak ayam broiler pasti banyak masalah yang dihadapi contohnya adalah tingkat kematian. Untuk menekan kerugian, para peternak sebaiknya memperhatikan faktor-faktor apa saja yang menyebabkan kematian ayam tersebut. Beberapa penelitian yang meneliti tentang ayam broiler menggunakan metode percobaan dan RAL. Namun masih belum ada yang meneliti mortalitas ayam broiler menggunkan komputasi. Untuk mengetahui metode mana yang lebih baik untuk memprediksi mortalitas pada peternakan ayam broiler dilakukan penelitian perbandingan metode Nä̈ve Bayes dan C4.5. Hasil dari perbandingan akan dievaluasi menggunakan confution matrix. Hasil dari pengujian data menggunakan confution matrix menghasilkan nilai akurasi dari metode $\mathrm{C} 4.5$ lebih besar dari pada metode Nä̈ve Bayes. Nilai akurasi dari metode C4.5 adalah 93\% dan nilai akurasi dari metode Nä̈ve Bayes adalah $88.66 \%$.
\end{abstract}

Kata kunci: mortalitas; ayam broiler; nä̈ve bayes; c4.5; perbandingan, prediksi.

\section{ABSTRACT}

Broiler chickens are the fastest type of livestock to harvest. But in raising broiler chickens, there must be many problems faced, for example the death rate. To reduce losses, farmers should pay attention to what factors cause the death of the chicken. Several studies that examined broiler chickens used experimental methods and RAL. However, there is still no research on the mortality of broilers using computing. To find out which method is better for predicting mortality at broiler chicken farms, a comparative study of Nä̈ve Bayes and C4.5 methods is conducted. The results of the comparison will be evaluated using the confution matrix. The results of testing the data using the confusion matrix resulted in an accuracy value of the C4.5 method greater than the Nä̈ve Bayes method. The accuracy value of the C4.5 method is $93 \%$ and the accuracy value of the Nä̈ve Bayes method is $88.66 \%$

Keywords: mortality; broiler chicken; nä̈ve bayes; c4.5; comparison; prediction.

\section{PENDAHULUAN}

Ayam broiler adalah jenis ayam jantan dan betina muda yang berumur sekitar 6-8 minggu yang dipelihara secara intensif, guna memperoleh daging yang optimal untuk memenuhi gizi [1]. Dalam pemeliharaan ayam broiler pasti banyak juga masalah yang dihadapi, salah satu contohnya adalah mengalami kerugian akibat kematian ayam broiler. Karena itu peternak ayam broiler harus mengetahui secara detail setiap langkah dan komponen penentu keberhasilan ternak ayam broiler [1].

Beberapa berita di kota-kota besar mengabarkan tentang kenaikan harga ayam broiler. Faktor kenaikan harga ayam broiler tersebut adalah mahalnya biaya produksi dan juga kurangnya pasokan ayam broiler yang dijual dipasaran. Salah satu faktor kurangnya pasokan ayam broiler adalah tingkat kematian pada ayam broiler yang tinggi [2]. 
Berbagai penelitian tentang ayam broiler telah dilakukan namun belum ada yang menggunakan metode komputasi. Maka dari itu akan dilakukan penelitian tentang mortalitas ayam broiler.

Perbandingan Algoritma Decision Tree (C4.5) Dan Nä̈ve Bayes Pada Data Mining Untuk Identifikasi Tumbuh Kembang Anak Balita menyimpulkan bahwa metode Naïve Bayes lebih baik dari metode C4.5 [3]. Perbandingan Akurasi Klasifikasi Tingkat Kemiskinan antara Algoritma C4.5 dan Nä̈ve Bayes menyimpulkan bahwa metode C4.5 lebih baik dari metode Nä̈ve Bayes [4].

Dari latar belakang diatas tersebut akan dilakukan penelitian dengan membandingkan 2 metode yaitu metode Nä̈ve Bayes dan metode C4.5 untuk melihat seberapa besar akurasi yang didapatkan.

\section{METODOLOGI PENELITIAN}

Berikut adalah kerangka penelitian yang akan dilakukan oleh peneliti yang akan dijelaskan pada gambar 1 .

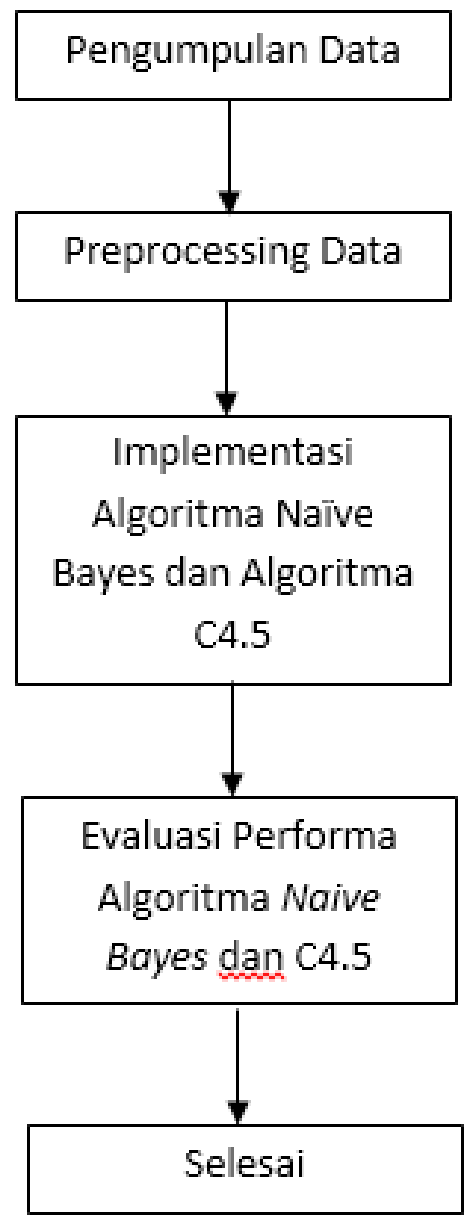

Gambar 1. Kerangka Penelitian

Berdasarkan Gambar 1. di atas, tahapan-tahapan dalam penelitian ini adalah sebagai berikut :

\subsection{Pengumpulan Data}

Tahap pertama pada penelitian ini adalah pengumpulan data dari sumber data yaitu peternakan ayam broiler. Pengumpulan data ini dilakukan dengan cara mengunjungi beberapa peternakan yang bekerja sama dengan PT. Semesta Mitra Sejahtera agar mendapatkan data yang valid.

Data yang didapatkan berjumlah 300 data kandang. Data yang digunakan adalah data pada tahun 2018 bulan Maret. Data yang digunakan juga data peternakan yang berada di Jawa Timur karena Jawa Timur adalah pemasok produksi ternak tingkat nasional [5].

Variabel yang didapatkan adalah jumlah populasi ayam broiler pada tiap kandang, jenis kandang yang digunakan, jenis ayam broiler yang diternakkan, BW (Body Weight) atau bobot ayam broiler, umur panen ayam broiler dan yang terakhir mortalitas ayam broiler. 


\subsection{Prepocessing Data}

Preprocessing Data adalah suatu proses/langkah yang dilakukan untuk membuat data mentah menjadi data yang berkualitas [6]. Dalam prepocessing data, yang akan dilakukan adalah melakukan transformasi data.

Proses transformasi data tersebut dilakukan menggunakan pengklasteran pada tiap atribut. Pengklasteran tersebut ditetapkan dari peraturan PT. Semesta Mitra Sejahtera. Peraturan tersebut merupakan peraturan yang tidak tertulis yang didapatkan dengan melakukan wawancara terhadap Branch Head dari PT. Semesta Mitra Sejahtera. Berikut adalah pengklasteran dari tiap atribut.

a) Populasi

Populasi dibagi menjadi 3 kelas yaitu kecil, sedang dan besar. Nilai dari tiap kelas adalah :

1) Kecil $=2500-7500$

2) Sedang $=8000-15000$

3) Besar $=\geq 16000$

b) Jenis kandang

Jenis kandang dibagi menjadi 2 yaitu open house dan close house.

c) Jenis ayam

Jenis ayam dibagi menjadi 2 jenis yaitu COBB dan ROSS.

d) $\mathrm{BW}($ Body Weight $)$

BW(Body Weight) dibagi menjadi 3 kelas yaitu :

1) Kurang $=<1.7 \mathrm{~kg}$

2) Sedang $=1.7-2 \mathrm{~kg}$

3) Besar $=>2 \mathrm{~kg}$

e) Umur panen

Umur panen dibagi menjadi 3 kelas yaitu :

1) Kurang $=<35$ hari

2) Sedang $=35$ hari

3) Lebih $=>35$ hari

f) Mortalitas

Mortalitas dibagi menjadi 2 kelas yaitu :

1) Besar $=>4$

2) Kecil $=\geq 4$

\subsection{Implementasi Algoritma Naive Bayes Dan Algoritma C4.5}

Pengujian data yang dilakukan untuk memprediksi mortalitas pada peternakan ayam broiler adalah menggunakan $K$-Fold Cross Validation. K-Fold Cross Validation berguna untuk membagi kumpulan data menjadi data latih dan data uji. K-Fold Cross Validation digunakan karena merupakan salah satu metode yang terbaik untuk memvalidasi data yang akan digunakan. Salah satu contoh dari K-Fold Cross Validation adalah 10-Fold Cross Validation. Teknik ini akan membagi kumpulan data menjadi 10 subset dengan ukuran yang sama, sembilan dari 10 subset data digunakan untuk pelatihan, sementara satu subset yang tertinggal digunakan untuk pengujian. Proses diulang selama sepuluh kali, dan hasil akhirnya diperkirakan sebagai tingkat kesalahan rata-rata pada contoh uji.

\subsection{Evaluasi Performa Algoritma Naive Bayes Dan Algoritma C4.5}

Evaluasi performa algoritma Nä̈ve Bayes dan algoritma C4.5 menggunakan confusion matrix untuk menghitung Akurasi, Presisi dan Recall. Berikut adalah tabel dari confution matrix:

Tabel 1. Tabel Confution Matrix [7]

\begin{tabular}{cccc}
\hline & & \multicolumn{2}{c}{ Dectected } \\
& & Positive & Negative \\
\hline \multirow{4}{*}{ Actual } & Positive & True Positive & False Negative \\
& & $(T P)$ & $(F N)$ \\
& Negative & False Positive & True Negative \\
& & $(F P)$ & $(T N)$ \\
\hline
\end{tabular}

Akurasi adalah tingkat kedekatan antara nilai prediksi dengan nilai aktual. Presisi adalah tingkat ketepatan antara informasi yang diminta dengan jawaban yang diberikan oleh sistem. Recall adalah 
tingkat keberhasilan sistem dalam menemumakan kembali informasi. Berikut perhitungna Akurasi, Presisi, dan Recall. Berikut adalah rumus untuk perhitungan Akurasi, Presisi, dan Recall [8]:

$$
\begin{aligned}
& \text { Akurasi }=\frac{T P+T N}{T P+F N+F P+T N} \\
& \text { Presisi }=\frac{T P}{T P+F P} \\
& \text { Recall }=\frac{T P}{T P+F N}
\end{aligned}
$$

\section{HASIL DAN PEMBAHASAN}

\subsection{Hasil Implementasi Algoritma Naive Bayes dan Algoritma C4.5}

Untuk menentukan berapa nilai K yang akan digunakan pada $K$-Folds Cross Validation dilakukan pengujian nilai K. Nilai K yang diuji adalah 5, 10 dan 15. Pengujian dilakukan pada aplikasi Weka 3.6. Perbandingan nilai dapat dilihat pada tabel 2.

Tabel 2. Perbandingan pengujian nilai K

\begin{tabular}{lrrrrrr}
\hline & \multicolumn{3}{c}{ Nä̈ve Bayes } & \multicolumn{3}{c}{$\boldsymbol{C 4 . 5}$} \\
\cline { 2 - 7 } & \multicolumn{1}{c}{$\mathbf{5}$} & $\mathbf{1 0}$ & $\mathbf{1 5}$ & $\mathbf{5}$ & $\mathbf{1 0}$ & \multicolumn{1}{c}{$\mathbf{1 5}$} \\
\hline Correctly & $89 \%$ & $88.667 \%$ & $88.667 \%$ & $93 \%$ & $93 \%$ & $93 \%$ \\
$\begin{array}{l}\text { Incorrectly } \\
\text { Relative }\end{array}$ & $11 \%$ & $11.33 \%$ & $11.33 \%$ & $7 \%$ & $7 \%$ & $7 \%$ \\
$\begin{array}{l}\text { absolute } \\
\text { error }\end{array}$ & $65.8431 \%$ & $63.9084 \%$ & $64.2237 \%$ & $58.237 \%$ & $57.145 \%$ & $57.3599 \%$ \\
& & & & & & \\
\end{tabular}

Setelah dilakukan pengujian pada nilai $\mathrm{K}$ tersebut, dapat dilihat nilai 10 adalah nilai yang terbaik diantara nilai yang diuji. Maka dari hasil pengujian tersebut akan dipilih nilai 10 untuk digunakan dalam K-Folds Cross Validation.

Pada proses 10-Folds Cross Validation, data yang berjumlah 300 akan dibagi rata menjadi 10 bagian yang mana 9 dari 10 data akan digunakan sebagai data latih dan 1 data yang lain digunakan untuk data uji. Proses dilakukan berulang 10 kali sehingga tiap data akan dicoba sebagai data uji. Setelah itu hasil akan dirata-rata untuk mendapatkan nilai akhir. Pada tabel 3 adalah nilai dari setiap 10-Folds Cross Validation yaitu 10 kali perhitungan menggunakan metode Nä̈ve Bayes.

Tabel 3. Tabel Perhitungan 10-Folds Cross Validation Metode Nä̈ve Bayes

\begin{tabular}{cccc}
\hline \multirow{2}{*}{ Fold } & \multicolumn{3}{c}{ Metode Nä̈ve Bayes } \\
\cline { 2 - 4 } & Akurasi & Presisi & Recall \\
\hline 1 & $90 \%$ & $0 \%$ & $0 \%$ \\
2 & $93.33 \%$ & $0.66 \%$ & $0.66 \%$ \\
3 & $90 \%$ & $0.5 \%$ & $0.33 \%$ \\
4 & $83.33 \%$ & $0 \%$ & $0 \%$ \\
5 & $90 \%$ & $0 \%$ & $0 \%$ \\
6 & $90 \%$ & $0 \%$ & $0 \%$ \\
7 & $76.66 \%$ & $0 \%$ & $0 \%$ \\
8 & $90 \%$ & $0 \%$ & $0 \%$ \\
9 & $90 \%$ & $0 \%$ & $0 \%$ \\
10 & $93.33 \%$ & $0.21 \%$ & $0.13 \%$ \\
\hline
\end{tabular}

Selanjutnya akan dilakukan perhitungan rata-rata pada nilai akurasi, nilai recall dan nilai presisi.

Tabel 4. Tabel perhitungan rata-rata 10-Folds cross validation metode nä̈ve bayes

\begin{tabular}{cc}
\hline & 10- Fold Cross Validation \\
\hline Akurasi & $88.66 \%$ \\
Presisi & $0.21 \%$ \\
Recall & $0.13 \%$ \\
\hline
\end{tabular}


Nilai akurasi dari metode Nä̈ve Bayes sudah baik namun bila dilihat nilai dari presisi dan nilai dari recall sangatlah kecil. Nilai tersebut kecil dikarenakan dari banyaknya angka nol yang didapat dari perhitungan nilai presisi dan nilai recall maka bila dirata-rata akan mendapat nilai yang relatif kecil. Pada tabel 5 adalah nilai dari setiap 10-Folds Cross Validation yaitu 10 kali perhitungan menggunakan metode C4.5

Tabel 5. Tabel perhitungan 10-Folds cross validation metode $\mathbf{C} 4.5$

\begin{tabular}{cccc}
\hline \multirow{2}{*}{ Fold } & \multicolumn{3}{c}{ Metode C4.5 } \\
\cline { 2 - 4 } & Akurasi & Presisi & Recall \\
\hline 1 & $93.33 \%$ & $0.66 \%$ & $0.66 \%$ \\
2 & $90 \%$ & $0.5 \%$ & $0.66 \%$ \\
3 & $93.33 \%$ & $0.6 \%$ & $1 \%$ \\
4 & $90 \%$ & $0.5 \%$ & $1 \%$ \\
5 & $96.66 \%$ & $0.75 \%$ & $1 \%$ \\
6 & $96.66 \%$ & $1 \%$ & $0.66 \%$ \\
7 & $80 \%$ & $0.2 \%$ & $0.33 \%$ \\
8 & $93.33 \%$ & $0.66 \%$ & $0.66 \%$ \\
9 & $100 \%$ & $1 \%$ & $1 \%$ \\
10 & $96.66 \%$ & $1 \%$ & $0.66 \%$ \\
\hline
\end{tabular}

Selanjutnya akan dilakukan perhitungan rata-rata pada nilai akurasi, nilai recall dan nilai presisi.

Tabel 6. Tabel perhitungan rata-rata 10-Folds cross validation metode $\mathbf{C 4 . 5}$

\begin{tabular}{cc}
\hline & 10-Fold Cross Validation \\
\hline Akurasi & $93.66 \%$ \\
Presisi & $0.68 \%$ \\
Recall & $0.76 \%$ \\
\hline
\end{tabular}

Nilai akurasi dari metode C4.5 sudah baik dan nilai dari presisi dan nilai recall juga bisa dikatakan besar. Nilai tersebut besar dikarenakan dari setiap perhitungan tidak ada yang bernilai nol, jadi bila diratarata akan mendapakan nilai yang relatif besar. Bila digambarkan dalam bentuk grafik sebagai berikut seperti pada gambar 2 :

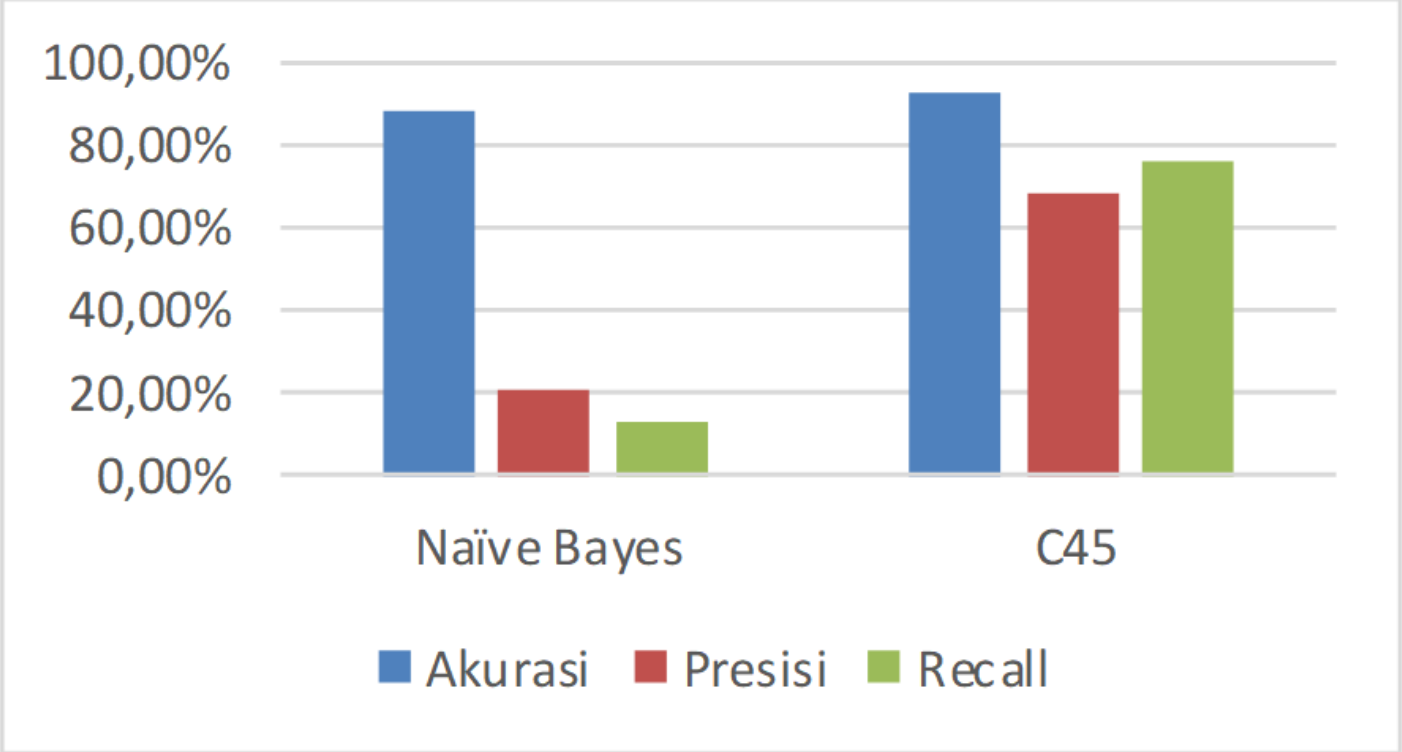

Gambar 2. Grafik Perbandingan Metode Nä̈ve Bayes dan Metode C4.5 


\subsection{Pembahasan}

Tabel 7. Tabel hasil perbandingan metode nä̈ve bayes dan metode $\mathrm{C} 4.5$

\begin{tabular}{lcc}
\hline \multicolumn{1}{c}{ Evaluation } & \multicolumn{2}{c}{ 10- Fold Cross Validation } \\
& Nä̈ve Bayes & C4.5 \\
\hline Accuration & $88.66 \%$ & $93 \%$ \\
Precission & $0.21 \%$ & $0.68 \%$ \\
Recall & $0.13 \%$ & $0.76 \%$ \\
\hline
\end{tabular}

Tingkat akurasi dari metode C4.5 lebih tinggi daripada metode Nä̈ve Bayes dikarenakan dalam metode C4.5 memprediksi kebenaran lebih banyak dibandingkan dengan metode Nä̈ve Bayes. Tingkat presisi dari metode C4.5 lebih tinggi daripada metode Nä̈ve Bayes dikarenakan tingkat ketepatan informasi yang diminta dengan jawaban yang diberikan oleh sistem lebih banyak.

Tingkat recall dari metode $\mathrm{C} 4.5$ lebih tinggi daripada metode Nä̈ve Bayes dikarenakan tingkat keberhasilan sistem dalam menemukan kembali informasi lebih tinggi daripada menggunakan metode Nä̈ve Bayes. Pada evaluasi menggunakan confution matrix dengan metode Nä̈ve Bayes didapatkan data sebagai berikut :

Tabel 8. Tabel confusion matrix metode nä̈ve bayes

\begin{tabular}{llcc}
\hline & & \multicolumn{2}{c}{ Detected } \\
\cline { 3 - 4 } & & Positive & Negative \\
\hline \multirow{2}{*}{ Actual } & Positive & 4 & 26 \\
& Negative & 8 & 262 \\
\hline
\end{tabular}

Hasil dari pengujian mendapatkan 266 data dari total 300 data diklasifikasikan dengan benar dan 34 data dari total 300 data dikatakan salah. Jika dilihat kembali maka akan terlihat berapa jumlah mortalitas besar yang benar dan salah maupun mortalitas kecil yang benar atau salah.

Dari tabel 8 diketahui nilai dari TP (True Positive) adalah 4 data karena terdapat 4 data adalah mortalitas besar yang diklasifikasikan benar. Nilai dari TN (True Negative) adalah 262 data karena terdapat 262 data mortalitas kecil yang diklasifikasikan benar.

Nilai dari FP (False Positive) adalah 8 data karena terdapat 8 data mortalitas kecil yang diklasifikasikan salah. Nilai dari FN (False Negative) adalah 26 data karena terdapat 26 data mortalitas besar diklasifikasikan yang salah.

Pada evaluasi menggunakan confution matrix dengan metode C4.5 didapatkan data sebagai berikut :

Tabel 9. Tabel confusion matrix metode C4.5

\begin{tabular}{llcc}
\hline & & \multicolumn{2}{c}{ Detected } \\
\cline { 3 - 4 } & & Positive & Negative \\
\hline \multirow{2}{*}{ Actual } & Positive & 23 & 7 \\
& Negative & 14 & 256 \\
\hline
\end{tabular}

Hasil dari pengujian mendapatkan 279 data dari total 300 data diklasifikasikan dengan benar dan 21 data dikatakan salah. Jika dilihat kembali maka akan terlihat berapa jumlah mortalitas besar yang benar dan salah maupun mortalitas kecil yang benar atau salah.

Dari tabel 4.9 diketahui nilai dari TP (True Positive) adalah 23 data karena terdapat 23 data adalah mortalitas besar yang diklasifikasikan benar. Nilai dari TN (True Negative) adalah 256 data karena terdapat 256 data mortalitas kecil yang diklasifikasikan benar. Nilai dari FP (False Positive) adalah 14 data karena terdapat 14 data mortalitas kecil yang diklasifikasikan salah. Nilai dari FN (False Negative) adalah 7 data karena terdapat 7 data mortalitas besar diklasifikasikan yang salah.

Dari pemrosesan yang telah dilakukan menggunakan metode C4.5 dengan 10-Fold Cross Validation mengasilkan tree sebagai berikut: 


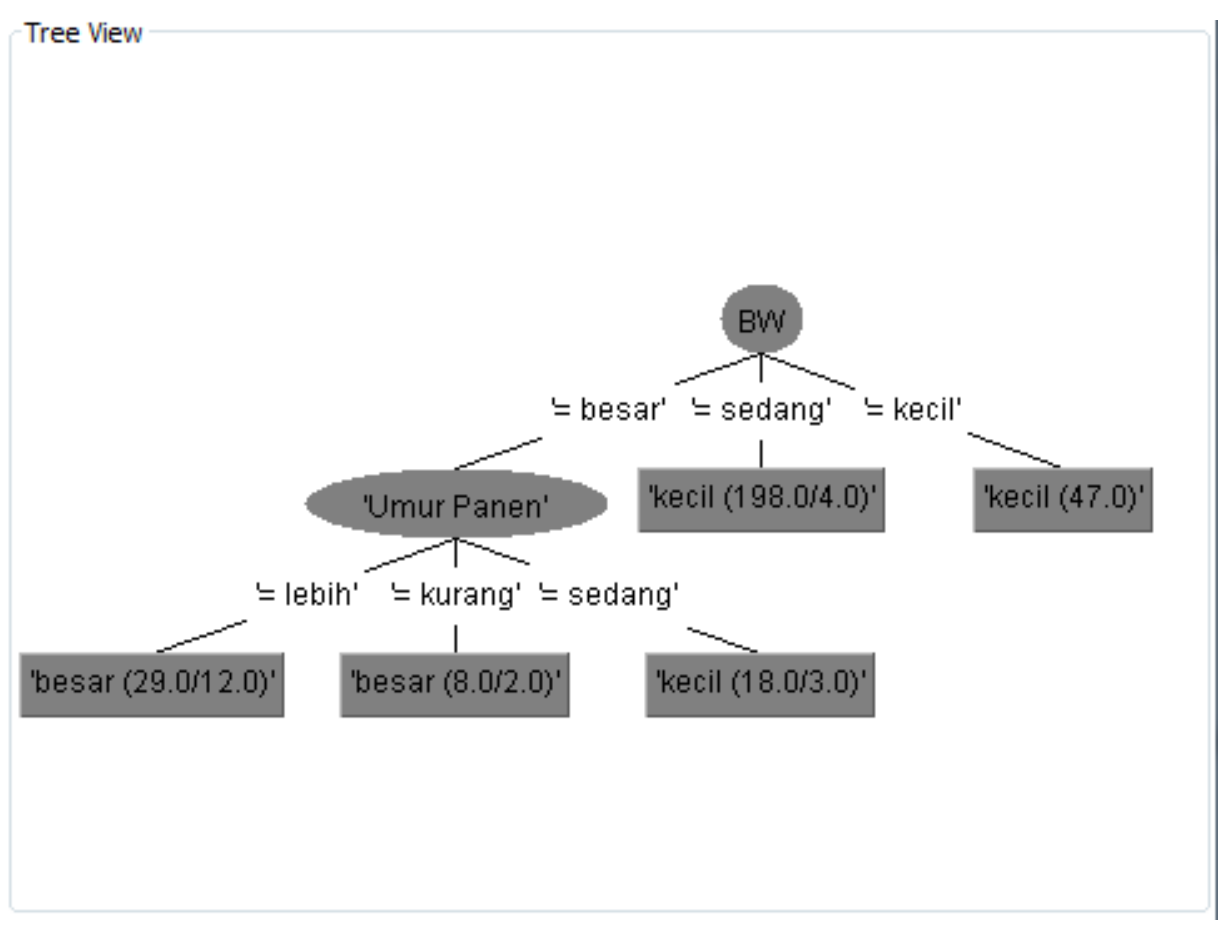

\section{Gambar 3. Gambar Tree Keputusan Metode C4.5}

Dari gambar 4.3 dapat dilihat Body Weight adalah node pertama dari tree keputusan. Tree tersebut memiliki 5 rule dan 6 cabang. Tree tersebut hanya menampilkan 2 dari 5 variabel yang ada karena ternyata hanya 2 variabel tersebut yang sangat mempengaruhi mortalitas pada ayam broiler.

Dari hasil penelitian yang telah dilakukan dan penjelasan dari perbandingan antara metode Nä̈ve Bayes dan metode C4.5 dapat disimpulkan bahwa untuk penelitian perbandingan metode Nä̈ve Bayes dan metode C4.5 untuk memprediksi mortalitas pada peternakan ayam broiler adalah metode C4.5 yang terbaik dikarenakan metode C4.5 menghasilkan akurasi, presisi dan recall yang lebih besar dari pada metode Nä̈ve Bayes.

\section{KESIMPULAN}

Berikut adalah kesimpulan yang dapat diambil, yaitu :

a) Penelitian perbandingan metode Nä̈ve Bayes dan metode C4.5 untuk memprediksi mortalitas pada peternakan ayam broiler adalah metode $\mathrm{C} 4.5$ yang terbaik dikarenakan metode $\mathrm{C} 4.5$ menghasilkan akurasi sebesar $93 \%$, presisi sebesar $0.68 \%$ dan recall sebesar $0.76 \%$.

b) Tree keputusan yang dihasilkan dari metode C4.5 menampilkan dua variabel yaitu variabel Body Weight dan variabel umur panen. Variable tersebut adalah variabel yang paling berpengaruh untuk memprediksi mortalitas pada ayam broiler.

\section{DAFTAR PUSTAKA}

[1] Nuril, B., Ubaidillah, M. (2013). Pengaruh Frekuensi Penyemprotan Desinfektan Pada Kandang Terhadap Jumlah Kematian Ayam Broiler.

[2] Republika.co.id. (2017). Harga Ayam Potong Naik di Malang

[3] Listiana., Mila. (2015). Perbandingan Algoritma Decision Tree (C4.5) Dan Naïve Bayes Pada Data Mining Untuk Identifikasi Tumbuh Kembang Anak Balita.

[4] Iskandar, D., Suprapto, Y. (2013). Perbandingan Akurasi Klasifikasi Tingkat Kemiskinan antara Algoritma C4.5 dan Naïve Bayes.

[5] Tribunnews. (2016). Jawa Timur Jadi Andalan Peternakan Nasional.

[6] Mayadewi, P., Roseli, E. (2015). Prediksi Nilai Proyek Akhir Mahasiswa Menggunakan Algoritma Klasifikasi Data Mining.

[7] Susanto, Heri. (2014). Data Mining Untuk Memprediksi Prestasi Siswa Berdasarkan Sosial Ekonomi, Motivasi, Kedisiplinan Dan Prestasi Masa Lalu. 
Jurnal SIMETRIS, Vol. 10 No. 1 April 2019

P-ISSN: 2252-4983, E-ISSN: 2549-3108

[8] Tampubolon, K., Saragih, H., Reza, B. (2013). Implementasi Data Mining Algoritma Apriori Pada Sistem Persediaan Alat-Alat Kesehatan. 